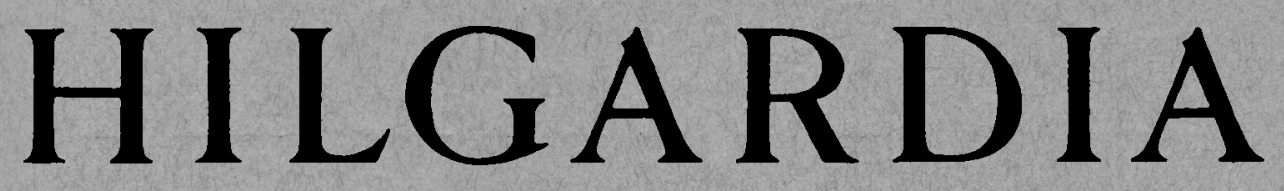

A Journal of Agricultural Science Published by the California Agricultural Experiment Station

\title{
VOLATILITY OF HERBICIDES UNDER FIELD CONDITIONS
}

B. E. DAY, E. JOHNSON and

J. L. DEWLEN 
Herbicidal formulations of 2,4-D, 2,4,5-TP, and amino triazole were tested for volatility under high summer temperature conditions in the Coachella Valley, California. The herbicides were applied to plots in cotton fields and the degree and extent of injury to surrounding cotton plants served as a measure of the volatility of the herbicides. Formulations of 2,4-D were found to be increasingly volatile in the order amine salts, acid, and low-volatile esters. It was determined that vaporization of the herbicides occurred predominantly during the daytime. A low volatile formulation of 2,4,5-TP appeared to be as volatile as similar formulations of 2,4-D but produced only minor injury symptoms on cotton. Amino triazole appeared to be entirely free of volatility hazard. 


\section{H I L G A R D I A}

A Journal of Agricultural Science Published by

the California Agricultural Experiment Station

VoL. 28

FEBRUARY, 1959

No. 11

\section{VOLATILITY OF HERBICIDES UNDER FIELD CONDITIONS ${ }^{1}$}

\section{B. E. DAY, ${ }^{2}$ E. JOHNSON, ${ }^{3}$ and J. L. DEWLEN ${ }^{4,5}$}

\section{INTRODUCTION}

Volatility is recognized as one of the hazards involved in using 2,4-D (2,4-dichlorophenoxyacetic acid) and similar compounds. The use of herbicidal preparations containing 2,4-D; 2,4,5-T (2,4,5-trichlorophenoxyacetic acid) ; or MCP (2-methyl, 4 chlorophenoxyacetic acid) in the form of highly volatile liquids is now prohibited by law in California. "Low-volatile" esters have most of the advantages of the more volatile forms with the exception perhaps of cost. The inorganic salts, considered to be nonvolatile, have largely been replaced by more-soluble organic salts, which can be formulated as liquids of higher concentrations and lower volume. Acid formulations, also considered to be nonvolatile, are marketed.

The usual methods of determining herbicide volatility are variations of the method reported by Zimmerman et al. (1939). ${ }^{\circ}$ The herbicide is exposed in a suitable dish or on filter paper within an enclosure in which susceptible plants are growing (Baskin and Walker, 1953; Hitcheock et al., 1953; King and Kramer, 1951; Marth and Mitchell, 1949; Mullison and Hummer, 1949; Zimmerman and Hitcheock, 1939; and Zimmerman et al., 1953). Plant response serves as an index of the volatility of formulations under test. Such methods permit comparison of the volatility of compounds and formulations on a relative basis but do not provide information directly usable in predicting the extent of hazards of use in the field. When an herbicide is applied in the field, it is deposited over a large area of soil and plant surfaces exposed to the direct rays of the sun. The temperatures of such surfaces are much higher than those encountered in the usual laboratory tests. A temperature of $150^{\circ} \mathrm{F}$ for soil surfaces exposed to the summer sun in California desert valleys is not unusual. No data on volatility of 2,4-D and 2,4,5-T formulations

${ }^{1}$ Paper No. 1055, University of California Citrus Experiment Station, Riverside. Received for publication January 20, 1958.

${ }^{2}$ Associate Plant Physiologist, University of California Citrus Experiment Station, Riverside.

${ }^{3}$ Field Supervisor, Agricultural Pest Control, California Department Agriculture, Los Angeles.

${ }^{4}$ Deputy Agricultural Commissioner, Riverside County.

${ }^{5}$ The authors are indebted to James Koehler, Robert Russell, and Earl Asker for technical assistance.

"See "Literature Cited" for citations referred to in the text by author and date. 
at such temperatures are available, and only limited field data are available for less rigorous conditions (Allen, 1950; Tafuro et al., 1950).

This report concerns field tests of low-volatile formulations of 2,4-D and 2,4,5-TP under summer temperature conditions encountered in the agricultural area of the Coachella Valley of California. The experiments were designed to explore the volatility of some so-called "low-volatile" formulations of herbicides under the extremely hot conditions of the Coachella Valley. The use of cotton as a test plant was merely a matter of convenience. The test fields were sacrificed for the purpose of the experiment. The main objective

TABLE 1

SPRAY FORMULATIONS AND RATES OF APPLICATIONS TO EXPERIMENTAL PLOTS IN A COACHELLA VALLEY COTTON FIELD, 1954

\begin{tabular}{|c|c|c|}
\hline Plot no. & Formulation & $\begin{array}{c}\text { Rate, } \\
\text { lbs/acre } \\
\text { (in 100 gal) }\end{array}$ \\
\hline 1 & Butoxyethanol 2, 4-D*. & 16 \\
\hline 2 & Butoxyethanol, 2,4-D*. & 8 \\
\hline 3 & Butoxyethanol 2,4-D*............ & 4 \\
\hline 4 & Propyleneglycol butyl ether $2,4-\mathrm{D} \dagger$. . & 4 \\
\hline 5 & Tetrahydrofurfuryl 2,4-D $\ddagger \ldots \ldots \ldots$ & 4 \\
\hline 6 & Butoxyethanol 2,4-D*..... & 2 \\
\hline 7 & Alkanolamine salts of $2,4-\mathrm{D} \$ \ldots \ldots$ & 4 \\
\hline 8 & Butoxyethanol $2,4-D^{*} \ldots \ldots \ldots \ldots$ & 1 \\
\hline 9 & 2,4-D acid emulsion $\|$. & 4 \\
\hline 10 & Propyleneglycol butyl ether $2,4,5$-TP $\ldots$ & 4 \\
\hline
\end{tabular}

* Weedone LV-4; supplied by the American Chemical Paint Company.

$\uparrow$ Esteron Ten-Ten; supplied by the Dow Chemical Company.

‡ Estercide D-4; supplied by the California Spray Chemical Corp.

$\$$ Formula 40 ; supplied by the Dow Chemical Company.

if Weedone 638; supplied by the American Chemical Paint Company.

$\checkmark$ Kuron A; supplied by the Dow Chemical Company.

was to answer the question, "How volatile are the so-called low-volatile esters, the alkanolamine salts, and the acids of 2,4-D and 2,4,5-TP ?" The conditions probably represent about the maximum for temperature on agriculturally useful land. They do, however, represent common temperature conditions in the southwestern United States and in many regions of the tropics.

\section{MATERIALS AND METHODS}

In the first experiment, commercial herbicidal formulations of 2,4-D alkanolamine salts, 2,4-D acid, and 2,4-D and 2,4,5-TP low-volatile esters (see table 1) were sprayed on plots, each 10 feet square, in a cotton field in the Coachella Valley in the summer of 1954. The cotton was second-year growth and somewhat spotty in stand and vigor. At the time of treatment, the plants were about 18 inches tall and in full bloom. The field was approximately four acres in area, irrigated from north to south by furrows 40 inches apart. A portable fence was made by constructing a frame 10 -feet square and 4 -feet high and covering the sides with building paper. This fence was placed around each plot, in turn, to prevent spray drift into adjacent areas during spraying. Plots were sprayed from a position outside the enclosure by reaching over the sides with a hand boom. The fence was moved from plot to plot 
by holding it overhead and transporting it in such a way as to avoid walking through sprayed plots. Air was calm, as shown by smoke tests both inside and outside the drift shelter at the time of spraying.

Applications were made with a compressed-air knapsack sprayer equipped with a flat-fan nozzle of 0.052 inch equivalent orifice diameter using a pressure of approximately 10 pounds per square inch. Materials were diluted with water and sprayed uniformly over the plot areas at the rate of 100 gallons per acre, covering both plants and soil. Water was withheld from the irrigation furrows which ran through the plots in order to eliminate the possibility of movement of the herbicides by this means. The materials and formulations applied are shown in table 1 . The rate per acre is computed as parent-acid equivalent (2,4-D in all plots except No. 10, in which 2,4,5-TP was used). If the 16-pound rate used in plot No. 1 seems high, it is nevertheless a reasonable rate for control of narrow-leaved cattail (Typha angustifolia L.), the species against which summer application of 2,4-D in the Coachella area is chiefly directed.

The extent of injury to the cotton plants surrounding the plots was recorded on July 10 (10 days after treatment) and at intervals of about two weeks until mid-September. The field was staked on a 20 -foot square grid, and the degree and extent of appearance of symptoms were estimated and plotted. On the first observation (July 10) presence or absence of epinasty and flower killing served as an index of injury. After growth modification symptoms had become well developed, four levels of cotton injury were recognized and mapped.

From July 1, the date of application, to and including August 31, soil surface temperatures in the cotton field were recorded at 2:30 p.m. almost daily. Readings were taken at the tops of rows and at the bottoms of furrows, both in the shade of cotton plants and in the sun. Measurements were made with a mercury thermometer by inserting the bulb about $1 / 2$ inch into the soil. Data on air temperature and wind direction and velocity were taken from official records at the Thermal Airport, located about two miles from the experimental field. These data are considered to be a close approximation of conditions existing at the test site.

Twelve sets of values for wind direction and velocity, taken at two-hour intervals during each 24-hour period, provided a basis for calculation of the total miles of wind moving from each of 16 points of the compass. Total airflow was calculated by multiplying wind velocity by duration. Night winds ( 8 p.m. to 6 a.m. readings) were calculated separately from day winds (8 a.m. to 6 p.m. readings) and average daily air movement for each period was computed.

A second experiment using the same methods throughout was conducted in 1955. Plots were treated on July 21 and observations were made at frequent intervals until September 30. At the time of treatment the cotton was in late bloom stage. Materials tested included amino triazole, alkanolamine salts of 2,4-D, isopropylamine 2,4-D and 2,4-D acid emulsion. All plots were treated at the rate of four pounds of herbicide per acre, acid equivalent basis. The mean maximum temperature for the first 42 days of the experiment was $104^{\circ} \mathrm{F}$. As in the previous year, the wind was predominantly from the south- 
east during the day and from the northwest at night. The distribution of cotton injury was mapped but because of the smaller areas affected, it was not feasible to classify different degrees of injury.

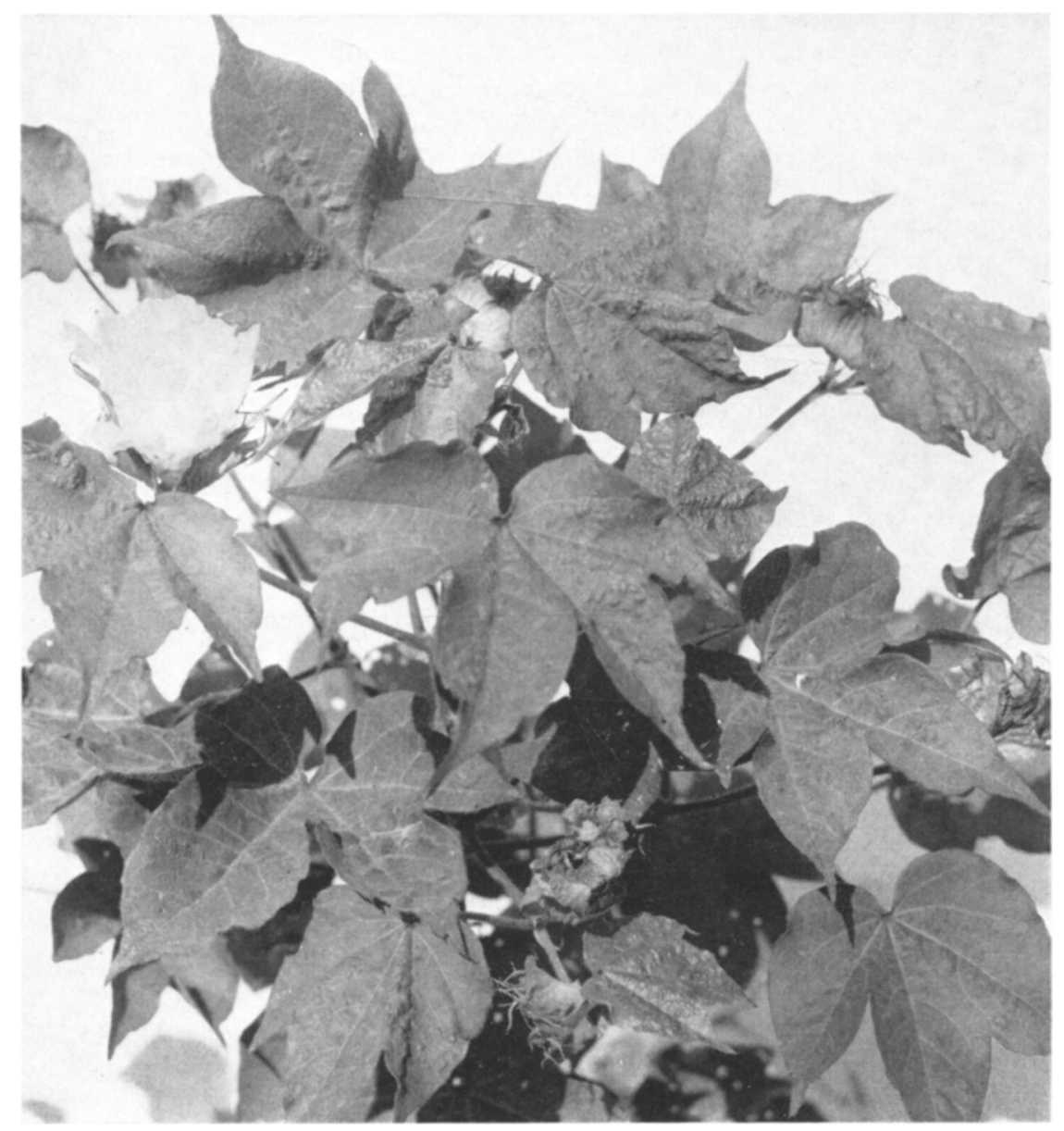

Fig. 1. Cotton plant showing "slight" symptoms of herbicide injury, namely, blossom injury (older flowers, bottom), crinkling of leaves, swelling of nodes, and some stem distortion. Plant located 160 feet northwest of plot 1 .

\section{RESULTS}

The distribution of plant injury symptoms in the plots treated in 1954 as observed 10 days after spraying the experimental plots is shown in figure 4. This is a rough sketch of the affected areas. Only the amine salt formulation failed to produce symptoms outside the plot (No. 7), although symptoms around the emulsifiable acid plot (No. 9) were slight. All of the ester formulations affected areas extending northwesterly from the plots in a fan-shaped 
pattern roughly proportional in extent to the concentration of the solution applied. Differences between ester formulations at the same concentration are not considered significant. Plants around the 2,4,5-TP plot (No. 10) did not show typical epinasty of stems; however, the petioles of leaves were recurved and blossom injury symptoms occurred throughout an area com-

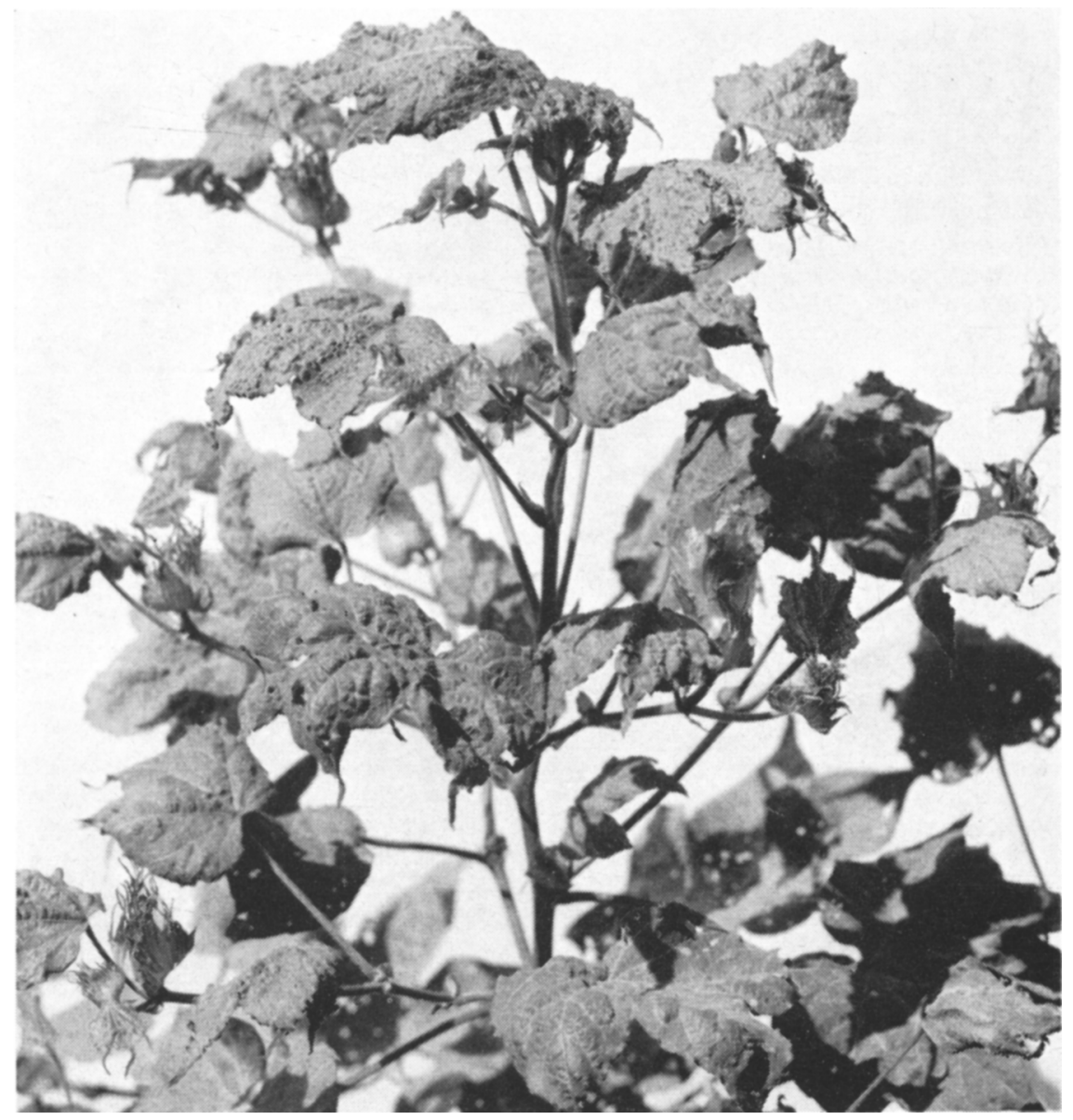

Fig. 2. Cotton plant showing "moderate" symptoms of herbicide injury. Plant located approximately 125 feet northwest of plot 1 .

parable in size, shape, and direction to the areas affected by 2,4-D ester formulations of the same concentration. Neither these nor any other abnormalities were detected on subsequent observations, although the plants within the 2,4,5-TP plot died as quickly as those in the 2,4-D plots.

Detailed observations were made on July 22, August 6, August 19, September 3, and September 17. Injury to the cotton plants was classified as "trace,". "slight," "moderate," and "severe." Plants representative of all except the "trace" classification are shown in figures 1,2 , and 3. 
The "trace" classification refers to areas where symptoms appeared only on occasional plants. This level of injury could not be shown clearly by photograph although it was readily identifiable in the field. Photographs were taken on August 19, fifty days after treatment of the plots.

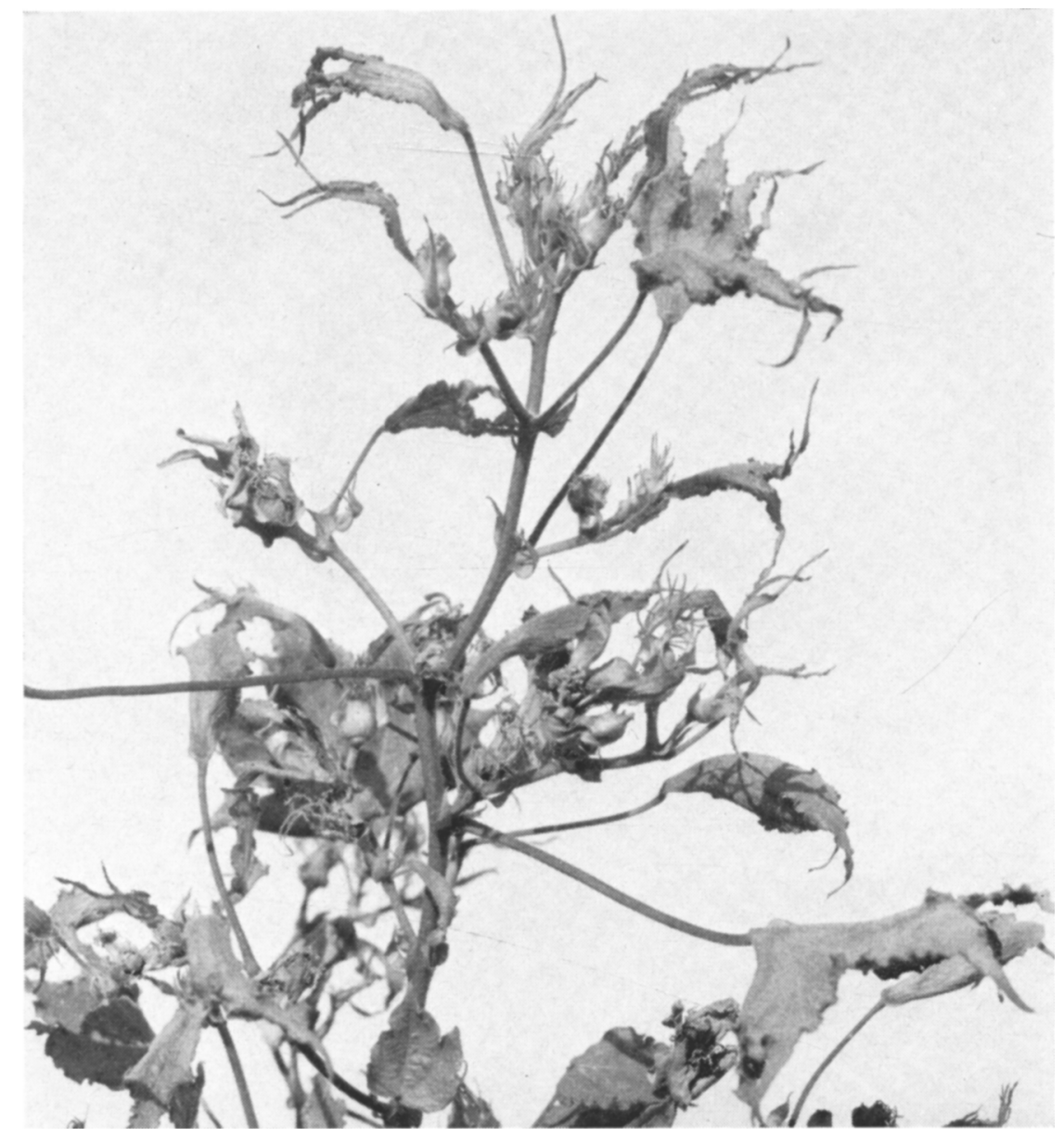

Fig. 3. Cotton plant showing "severe" symptoms of herbicide injury. Plant located approximately 60 feet northwest of plot 1 .

With increasing time after treatment, the general pattern of injury continued to retain its original fan shape. Symptoms continued to spread outward until the entire northwest portion of the field was more or less affected. The familiar symptoms of 2,4-D injury on cotton foliage-namely, strapshaped leaves, elongated terminal growth, and malformations-gradually increased in damaged areas, except that those plants nearest the 2,4-D-ester plots made no further growth after the treatment and eventually died. A striking symptom was the death of the blossoms, which remained on the 

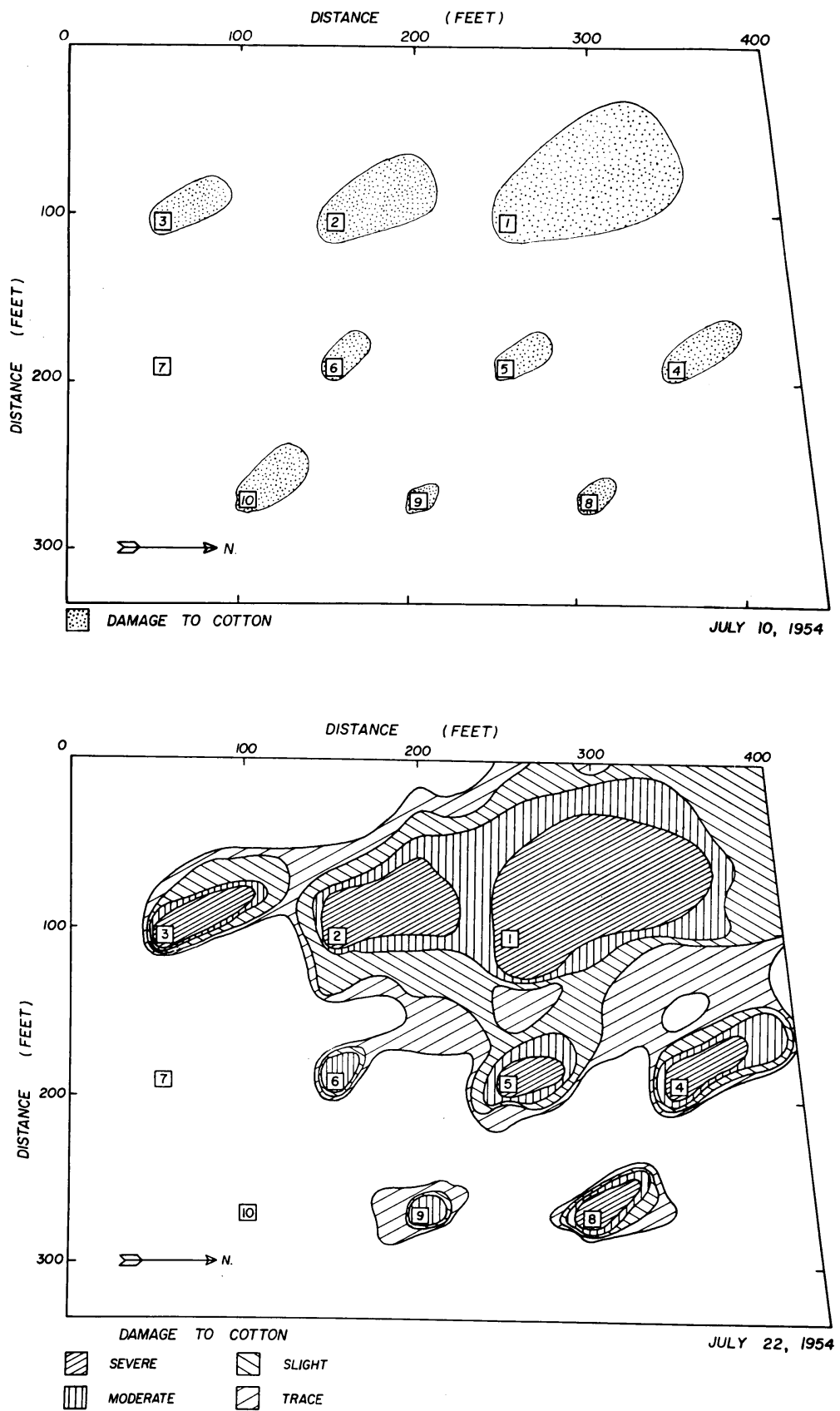

Fig. 4. Diagrams showing degree and extent of injury to plants in a Coachella Valley cotton field 10 days (above) and 22 days (below) after application of herbicides to 10 -footsquare experimental plots. (For description of plot treatments, see Table 1.) 

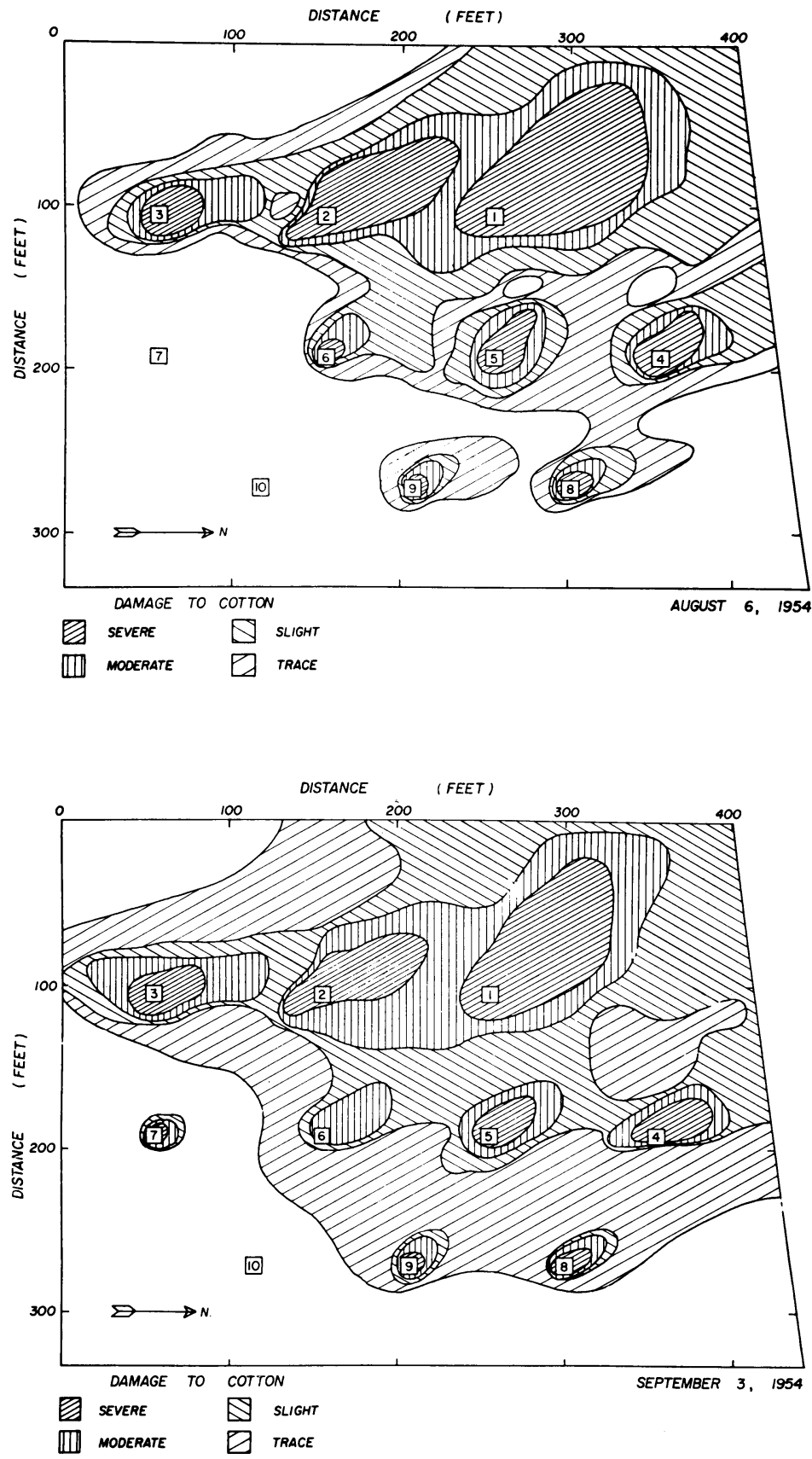

Fig: 5. Diagrams showing degree and extent of injury to plants in a Coachella Valley cotton field 37 days (above) and 65 days (below) after application of herbicides to 10-footsquare experimental plots. (For description of plot treatments, see Table 1.) Observe delayed appearance of symptoms around the plot (No. 7) treated with alkanolamine salts of 2,4-D. 
plants after they had shriveled. Where injury was moderate or severe, few if any bolls set after exposure, and those which did set were small, fewseeded, and with fragile lint. Where injury was less severe, some blossoms were killed and some leaf modifications occurred, but the plants recovered and resumed normal growth.
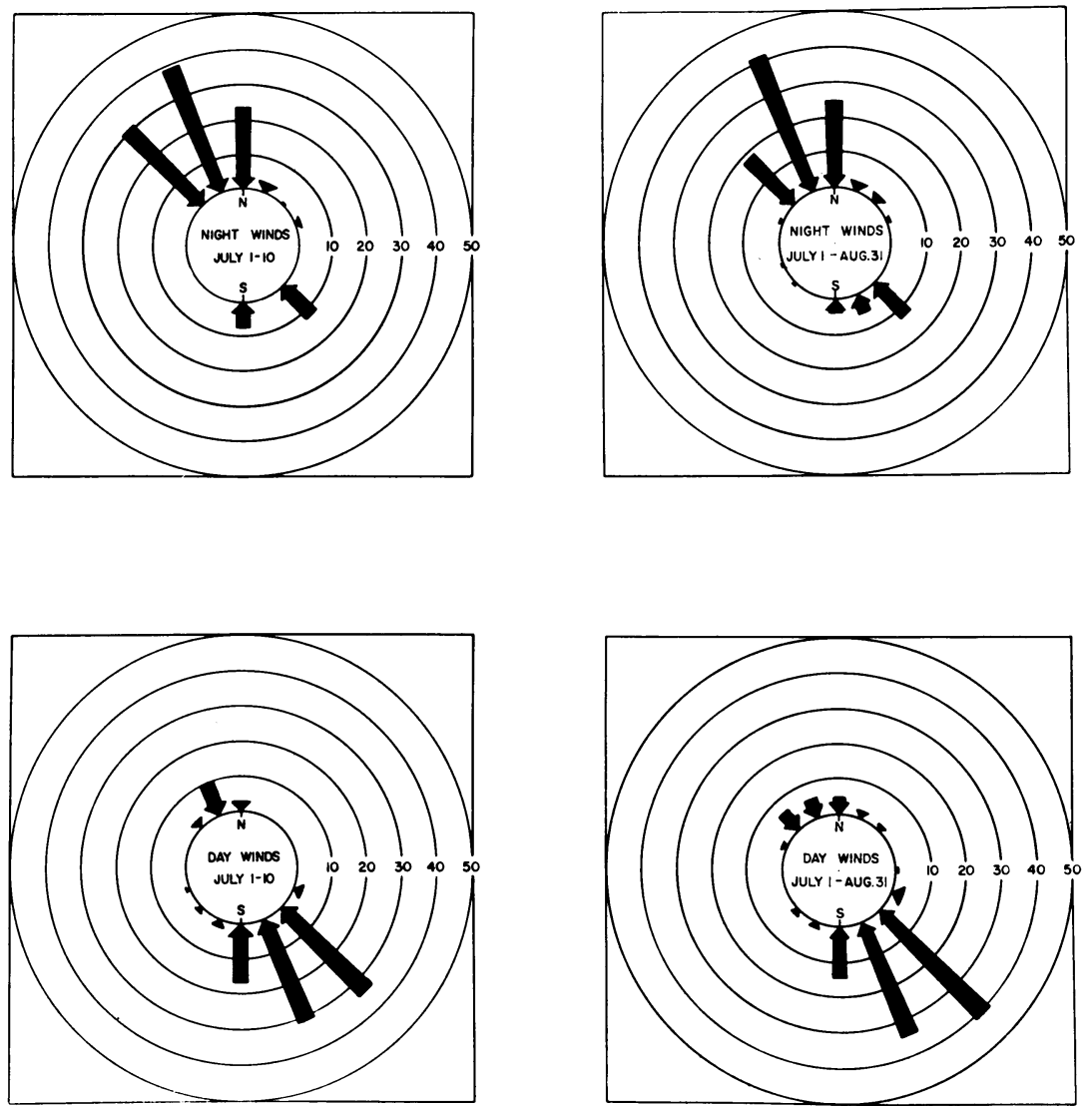

Fig. 6. Analysis of air movement (day winds and night winds) from 16 points of the compass. Calculated average miles of winds per day (velocity $\times$ duration) are represented by length of arrows. Data for the first 10 days of the experiment, shown in charts at the left, are also included in charts for the two-month period. Note consistent pattern of prevailing southeasterly winds in the daytime and northwesterly winds at night.

Figures 4 and 5 show the progressive spread of cotton injury from July 22 to September 3 (22 to 65 days after treatment). Results on August 19 were intermediate between those of August 6 and September 3, and observations of September 17 differed little from those shown for September 3.

The patterns of injury at once suggest the influence of wind, and a study of the data on air movement bears this out (fig. 6). Wind velocities were normally moderate, rarely exceeding 20 miles per hour. Wind data for the first 10 days of the experiment are shown separately for comparison with 
the initial pattern of symptoms (fig. 4). The remarkably consistent prevailing winds in this area fell into two patterns, night winds and day winds, which were very nearly equal in duration and velocity but opposite in direction. The general direction of airflow was from northwest to southeast at night, and from southeast to northwest during the day. The air was usually calm or with light variable movement for a short time prior to and following sunrise and sunset. Northwesterly night winds usually reached highest velocity (10 to 20 miles per hour) around midnight, and southeasterly winds reached similar peak velocities in early afternoon.

\section{TABLE 2}

AIR AND SOIL TEMPERATURES IN EXPERIMENTAL VOLATILITY PLOTS, JULY AND AUGUST, 1954

\begin{tabular}{|c|c|c|c|c|c|}
\hline & \multicolumn{5}{|c|}{ Temperature, ${ }^{\circ} \mathrm{F}(2: 30$ p.m. $)$} \\
\hline & \multirow{3}{*}{ Air } & \multicolumn{4}{|c|}{ Soil } \\
\hline & & \multicolumn{2}{|c|}{ Bottom of furrow } & \multicolumn{2}{|c|}{ Row surface } \\
\hline & & In shade & In sun & In shade & In sun \\
\hline \multicolumn{6}{|l|}{ July 1 to 10} \\
\hline $\begin{array}{l}\text { Average } \ldots \ldots \ldots \ldots \\
\text { Highest reading }\end{array}$ & $106^{*}$ & 106 & 138 & 105 & 146 \\
\hline Highest reading. & 115 & 122 & 153 & 108 & 151 \\
\hline \multicolumn{6}{|l|}{ July 1 to August 31} \\
\hline Average .......... & $103 \dagger$ & 108 & 137 & 108 & 139 \\
\hline Highest reading. & 117 & 122 & 158 & 129 & 156 \\
\hline
\end{tabular}

* Average daily maximum $109^{\circ} \mathrm{F}$.

$\dagger$ Average daily maximum $105^{\circ} \mathrm{F}$.

A summary of soil and air temperature data for the first 10 days of the experiment and for the months of July and August is given in table 2. The highest single reading for the two-month period was $158^{\circ} \mathrm{F}$ in the soil at the bottom of the furrow, the maximum air temperature that day being $117^{\circ} \mathrm{F}$.

Distribution of cotton injury from plots treated in 1955 is shown in figure 7. Data given are for the September 30 observation, 71 days after the plots were sprayed. The affected areas adjacent to the plots treated with 2,4-D acid and alkanolamine salts were similar in size and orientation with the prevailing winds to injury patterns obtained with the same materials in the previous experiment. Results obtained with the isopropylamine salt were approximately the same as obtained with the alkanolamine formulation. Symptoms of amino triazole injury did not appear outside the treated plot.

\section{DISCUSSION}

Both the alkanolamine and isopropylamine salts at first appeared not to affect any of the plants outside the plots, but after six weeks symptoms developed on plants to the northwest. This suggests the possibility that a more 
volatile product was formed by a change in the chemical composition of the residue, or that a low order of volatility caused delayed injury by accumulative action. 2,4-D acid, previously considered to be essentially a nonvolatile material, was appreciably volatile in the commercial formulation tested, although much less so than the low-volatile esters. Amino triazole would appear to be free of volatility hazard under these conditions.

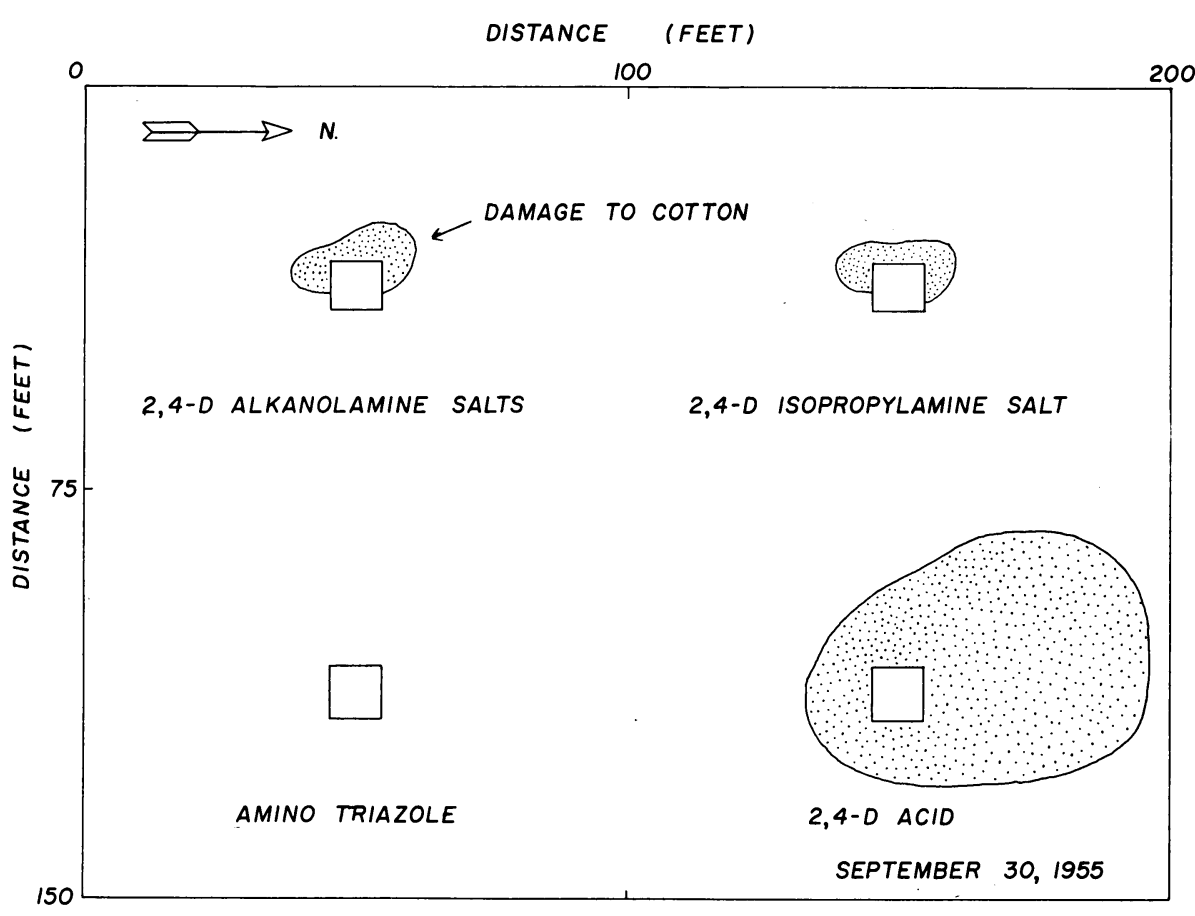

Fig. 7. A diagram showing the distribution of cotton injury (shaded areas) 71 days after treatment of plot areas with commercial formulations of the herbicides shown. Results obtained with isopropylamine salt were approximately the same as those obtained with the alkanolamine formulation. Symptoms of amino triazole injury did not appear outside the treated plot. The symptoms of 2,4-D injury on cotton foliage gradually increased in damaged areas.

It is evident that the distribution of herbicide fumes was governed by the diurnal pattern of prevailing winds. The vapors were moved predominantly in a northwesterly direction by daytime winds from the southeast. Since northwesterly winds at night were about equal in duration and velocity to daytime winds, vapors generated from the treated plots in the daytime were evidently sufficient to affect cotton plants. At night there was not enough vapor to affect the plants. For similar reasons it is apparent that the blowing of contaminated dust was not an important factor in producing symptoms on cotton outside the plots. It would also appear that movement of the herbicide residues by insects was not a major factor since this mode of movement could not account for the wide difference in distribution patterns observed. 
The climatic conditions of this experiment are considered to provide an unusually rigorous test of herbicide volatility hazard. The high soil and air temperatures and intense sunlight prevailing during the experiment were the maximum conditions favoring herbicide volatility likely to be encountered in any areas where crops are grown. With the exception of amino triazole, none of the materials tested can be considered to be completely free of volatility hazards under these conditions.

\section{SUMMARY}

Herbicidal formulations of 2,4-D alkanolamine and isopropylamine salts, 2,4-D acid, 2,4-D low-volatile esters, 2,4,5-TP low-volatile ester, and amino triazole were sprayed on plots in cotton fields in the Coachella Valley, California, under high summer temperature conditions. Each plot was surrounded by an enclosure at the time of spraying, to prevent spray drift into adjacent areas. The degree and extent of injury to the cotton plants surrounding the plots served as a measure of the volatility of the herbicides.

The amine salts caused slight injury to surrounding cotton, with the first symptoms appearing six weeks after treatment. The 2,4-D acid formulation was somewhat more volatile, affecting an area several times larger than the treated plot. Vapors from three low-volatile ester formulations of 2,4-D injured plants over large areas of the field in patterns roughly proportional in size to the amount of herbicide applied to the plots. The experimental fields were in an area in which prevailing day and night winds were about equal in duration and velocity but opposite in direction. Patterns of injury indicated that sufficient vapor was generated from the plots in the daytime to affect cotton. At night the amount of vapor was not enough to cause injury. A low-volatile formulation of 2,4,5-TP appeared to be as volatile as similar formulations of 2,4-D but produced only minor plant injury symptoms. No symptoms of amino triazole injury appeared outside the treated area.

With the exception of amino triazole, none of the formulations tested may be considered entirely free of volatility hazard under the conditions of these experiments. 


\section{LITERATURE CITED}

ALLEN, W. W.

1950. Progress report on volatility of some esters of 2,4-D. Proc. Third Ann. Southern Weed Conf. Pp. 7-12.

BASKin, A. David, and E. A. WALKER

1953. A biological method for the determination of extent of volatility of esters of 2,4-D and/or 2-4,5-T. Proc. Ann. Northeastern Weed Control Conf. Pp. 47-50.

Hitchcock, A. E., P. W. Zimmerman, and Henry Kirkpatrick, Jr.

1953. A simple, rapid biological method for determining the relative volatility of esters of 2,4-D and 2,4,5-T. Boyce Thompson Inst. Contrib. 17:243-63.

King, Lawrence J., and John A. Kramer, JR.

1951. Studies on the herbicidal properties and volatility of some polyethelene and polypropylene glycol esters of 2,4-D and 2,4,5-T. Boyce Thompson Inst. Contrib. 16: 267-78.

Marth, Paul C., and John W. Mitchell

1949. Comparative volatility of various forms of 2,4-D. Bot. Gaz. 110:632-36.

Mulison, Wendell R., and Richard W. Hummer

1949. Some effects of the vapor of 2,4-dichlorophenoxyacetic acid derivatives on various field crop and vegetable seeds. Bot. Gaz. 111:77-85.

Tafuro, A. J., J. D. Van Geluwe, and L. E. Curtis

1950. Drift and volatility comparison of an amine salt and ester form of 2,4-D under field conditions. Northeastern States Weed Control Conf. Proc. Pp. 31-35.

Zimmerman, P. W., and A. E. HitchCock

1939. Experiments with vapors and solutions of growth substances. Boyce Thompson Inst. Contrib. $10: 481-508$.

Zimmerman, P. W., A. E. HitchCock, and Henry KirkPatrick, JR.

1953. Methods for determining relative volatility of esters of 2,4-D and other growth regulants based on response of tomato plants. Weeds $2: 254-61$.

Zimmerman, P. W., A. E. Hitchcock, and Frank Wilcoxon

1939. Responses of plants to growth substances applied as solutions and vapors. Boyce Thompson Inst. Contrib. 10:363-80. 

The journal Hilgardia is published at irregular intervals, in volumes of about 600 pages. The number of issues per volume varies.

Subscriptions are not sold. The periodical is sent as published only to libraries, or to institutions in foreign countries having publications to offer in exchange.

You may obtain a single copy of any issue free, as long as the supply lasts; please request by volume and issue number from:

Agricultural Publications

Room 22, Giannini Hall

University of California

Berkeley í, California

The limit to nonresidents of California is 10 separate issues on a single order. A list of the issues still available will be sent on request. 